\title{
Five new species of Dichaetomyia from the Malagasy Subregion (Diptera: Muscidae)
}

\author{
Eberhard Zielke \\ Institute of Biodiversity and Ecosystem Research, Bulgarian Academy of Sciences, 1 Tsar Osvoboditel Blvd, 1000 Sofia, \\ Bulgaria, eo.zielke@abv.bg \\ http://zoobank.org/AD3AA01D-B070-461A-A1A0-6ED7B06C1564
}

\begin{abstract}
Five new species of the genus Dichaetomyia are described from Madagascar. Two species, Dichaetomyia analama sp. n. and D. necoa sp. n. belong to the subgenus Panaga. Three other species, D. amboha sp. n., D. blackia sp. n. and D. tantelya sp. n. are members of the subgenus Dichaetomyia. The body colour in normal light conditions of the five species is predominantly yellowish or grey to dark brown or blackish like most of the Afrotropical species of Dichaetomyia.
\end{abstract}

Keywords: descriptions, diagnosis, Phaoniinae, subgenus Panaga, subgenus Dichaetomyia

\section{Introduction}

Among the Madagascan muscids studied since 2015 at the Institute of Biodiversity and Ecosystem Research (IBER) in Sofia, Bulgaria, there were several specimens of the genus Dichaetomyia Malloch, 1921.The genus is represented in the Afrotropical Region by two subgenera, Dichaetomyia Malloch and Panaga Curran, 1928. The latter is restricted to Africa, whereas Dichaetomyia s. str. occurs worldwide. The majority of the species of Dichaetomyia known from Madagascar belongs to Dichaetomyia s. str. The current paper deals with five species new to science. Three species belong to the subgenus Dichaetomyia s. str. and two to the subgenus Panaga.

\section{Materials and methods}

The studied Madagascan Muscidae had mostly been collected in the last 25 years and the specimens for the current study were provided by various entomological institutions. The unidentified muscid specimens origin- ated from the Moravian Museum. The flies were isolated from the stored in ethanol remains of insect traps. Most of the insects that had been left among the remains were in very poor condition, only a small portion of the Muscidae found were suitable for processing and identification. The flies were cleaned and mounted on a pin as recently described (Zielke, 2021b). Several of the selected specimens were rather fragile and despite the careful handling some of them lost body parts during the preparation, these parts were transferred into a gelatine capsule that was then attached to the staging pin.

The vials with the remains contained locality labels, but unfortunately information about the collectors were not found or could not be deciphered. Therefore, the inscriptions of the locality labels are reproduced verbatim but without naming collectors.

The identification key for the Madagascan Muscidae published by Couri et al. (2006) was used to identify the flies. Since this is the only actual key for the identification of species of Dichaetomyia from Madagascar, reference is made to the key several times without mentioning the authors and the year of publica- 
tion each time. The new species described in the present contribution are not distinguished by striking blue, green or purple colours as known only from some Madagascan species (Zielke, 1972, 2020; Couri et al., 2006). In normal light conditions they are characterised by yellowish to grey or dark brown body parts, as is typical for most African species of the genus. For this reason, the identification keys of van Emden (1942a, $1942 \mathrm{~b}$ ) for the African species of Dichaetomyia and of Pont (1978) for the species of the Comoro Islands were also consulted before a species was described as new to science. In addition, the newly described species were compared with the descriptions of those Afrotropical species of Dichaetomyia (Pont, 1969; Zielke, 1971, 1974) which had not been included in the above-mentioned identification tables of van Emden and Pont.

The subgenus Panaga is mentioned in brackets as part of the name in the heading of the description below of each species belonging to this subgenus, whereas the subgenus Dichaetomyia is not explicitly added to the name of described species.

Morphological terminology follows McAlpine (1981), but postpedicel (Stuckenberg 1999) is used instead of "first flagellomere" as proposed by McAlpine. Moreover, as already suggested earlier (Zielke 2020), the lateral width of the postpedicel of antenna is called "depth" and usually refers to the greatest depth of the postpedicel. Information about the width of frons always refers, if not stated otherwise, to the shortest distance between the margins of the eyes. Only the postsutural intra-alar setae are called intra-alar setae. The intra-alar setae of the presutural part of the mesonotum are referred to as posthumeral and presutural setae as has already been done for example by Gregor et al. (2002, 2016) and Nihei \& Carvalho (2009). Body length was measured in millimetres $(\mathrm{mm})$.

The specimens were studied using a Zeiss Stemi SV6 stereomicroscope and images were created by means of combination of a Zeiss Discovery 8 stereomicroscope and an AxioCam ERc5s camera as described previously (Zielke, 2020, 2021a).

The undetermined material and numerous identified specimens of Dichaetomyia were examined and compared. The specimens including paratypes and holotypes were kindly loaned for examination to IBER by the entomological departments of: Moravian $\mathrm{Mu}-$ seum, Brno, CZ; California Academy of Sciences, San Francisco, CA/USA; Natural History Museum Berlin, $\mathrm{D}$, the Natural History Museum London, UK, the KwaZulu-Natal Museum Pietermaritzburg, SA and
Oxford University Museum of Natural History, UK. In addition, during a visit to the Natural History Museum in London in autumn 2019, several specimens of the Madagascan species of Dichaetomyia were also compared with corresponding material from the collection of Muscidae kept there.

Unless otherwise stated in the description of the individual species, all specimens will be returned to those collections that loaned the material to IBER.

\section{Results}

Additions to the descriptions (Applicable to each of the females of the described new species)

The females of the four new species of Dichaetomyia from Madagascar described below have several taxonomic features in common, which practically do not differ. Therefore, they have no diagnostic value for distinguishing these species from one another. However, for completeness, these criteria have to be mentioned in the basic characterisation of each of the new species. In order to avoid redundant listings of criteria without diagnostic value, the almost identical taxonomic features are compiled in this chapter, which is therefore to be regarded as an elementary part of the description of each of the four new species of which the female is known. If a characteristic of a species differs significantly from this general characterisation, the difference is mentioned in the individual description. The compilation of taxonomic features below refers to the females of the species: Dichaetomyia (Panaga) analama sp. n., Dichaetomyia (Panaga) necoa sp. n., Dichaetomyia amboha sp. n. and Dichaetomyia tantelya sp. n.

Head. Dichoptic; eyes with a few, scattered very small hairs, facets of inner and outer side of eye of about equal size. Parafacial bare and distinctly tapering along the entire length. In profile, upper mouth margin about in line with profrons. Arista approximately twice as long as length of postpedicel. Upper half of lateral surface of gena bare, lower margin with black setae and some small setulae. Palpus slender and clavate.

Thorax. Acrostichal setae $0+1$, seta not half as long as posterior dorsocentral seta; two postpronotal setae, the outer one somewhat longer; two notopleural setae, notopleuron with few small hairs; two intra-alar setae. Postalar declivity and suprasquamal ridge bare. Prosternum haired; anepimeron with a tuft of setulae above and some scattered seta-like hairs on posterior 


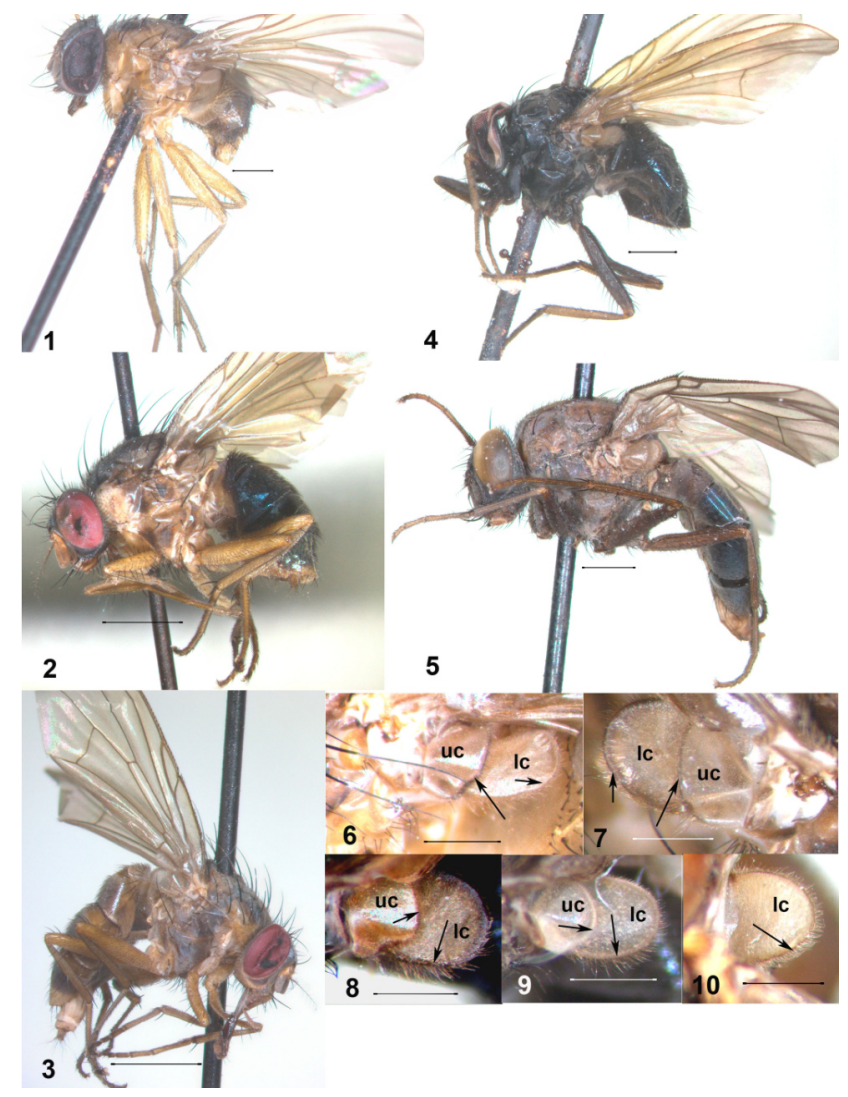

Figs 1-5. Lateral view of the five newly described species of Dichaetomyia: (1) q holotype, D. analama sp. n.; (2) $q$ holotype, D. amboha sp. n.; (3) 9 holotype, D. necoa sp. n.; (4) $\widehat{\jmath}$ holotype, D. blackia sp. n. (5) + paratype, D. tantelya sp. n. Abdomen of $D$. amboha and D. tantelya in normal light conditions predominantly brownish to dark brown/ blackish, in photographic exposure unusually bluish shiny. (figures 1, 4, 5 bar: $1 \mathrm{~mm}$; figures 2, 3 bar: $2 \mathrm{~mm}$ ). Figs 6-10. Upper (uc) and lower (lc) calypters of the holotypes of the new species of Dichaetomyia: (6) D. analama sp. n., upper calypter with dark brown framed margin (long arrow), lower calypter without a framed margin (short arrow); (7) D. necoa sp. n., slightly brownish transparent calypters, both with a framed dark margin; (8) D. blackia sp. n., lower calypter predominantly brownish transparent with dark brown margin, upper calypter yellowish brown transparent with brown framed margin (short arrow); (9) D. amboha sp. n., both calypters whitish transparent with almost whitish margins (short arrow) or in certain light conditions with more or less whitish brownish margin (long arrow); (10) D. tantelya sp. n., lower calypter yellowish-white transparent with brown framed margin (arrow), upper calypter hardly visible as it points upwards at right angle to the lower calypter (figures 6-10 bar: $0.5 \mathrm{~mm}$ ).

surface; proepimeral area, katepimeron and meron bare. Posterior spiracle with black setae at lower mar- gin. Katepisternal setae $1+2$, the lower one distinctly closer to the posterior seta than to the anterior one. Scutellum with a pair of strong apical and strong lateral setae; basal and preapical setae much shorter but clearly differentiated from ground hairs.

Wing. Membrane hyaline, cross-veins and surrounding membrane not infuscate. Vein $M$ somewhat diverging from vein $\mathrm{R} 4+5$, very slightly curved forward to $\mathrm{R} 4+5$ before reaching wing margin. Cross-vein $\mathrm{r}-\mathrm{m}$ clearly anterior to the point where vein $\mathrm{R} 1$ enters costa; distal cross-vein dm-cu sinuous and oblique. Knob and stem of haltere pale yellow.

Legs. Pulvilli and claws distinct but not as long as the corresponding tarsomere. Fore femur with complete rows of posterodorsal, posterior and posteroventral setae, the posterodorsals and posteriors barely as long as depth of femur at point of insertion, posteroventrals somewhat longer than depth of femur. Mid tibia with two strong posterior setae, about twice as long as diameter of tibia. Hind tibia without a long distinct posterodorsal seta.

Abdomen without specific pattern. Sternite 1 laterally with few setulose hairs. Female genitalia were not investigated.

Dichaetomyia (Panaga) analama n. sp. (Figs 1, 6, 11, 16, 20)

Material examined: $q$ holotype from "Madagascar, Andasibe, Analamazaotra, S. R., Perinet, Circuit Indri, $\mathrm{S} 18.935882^{\circ}-938042^{\circ} \mathrm{E} 48.419051^{\circ}-419332^{\circ}$, ca. 950 $\mathrm{m}$, screen sweeping, 16.01.2017'. The specimen is lacking the fore legs; the left mid tibia with the tarsi fell off during preparation and was transferred into a gelatine capsule, which was then attached to the staging pin. The holotype will be located in the Entomological Department of the Moravian Museum, Brno, CZ.

Etymology: The epithet analama of the species' name is an adjective in feminine case and derives (somewhat modified) from the name of the Analamazaotra Reserve, the area where the holotype was found.

Description (female) [see also "Additions to the descriptions" p. 66]: Head (Figs 11, 16). Ground-colour greyish brown. Eyes practically without microscopic hairs. Frons at vertex about 0.26 times as wide as maximum width of head, almost parallel-sided only weakly dilated towards the anterior margin, at level of anterior ocellus about 3.2 times as wide as the distance 
between the outer margins of posterior ocelli and at anterior margin of frontal vitta directly above lunule about 3.7 times as wide. Fronto-orbital plate at narrowest point about twice as wide as anterior ocellus. Frontal triangle slender, not very clearly demarcated, anterior part strongly tapering; from certain viewing angle the anterior tip reaching second pair of anterior frontal setae. Parafacial at level of antenna basis slightly broader than the width of postpedicel and at the lower end barely as broad as anterior ocellus. Genal depth below lowest eye margin (Fig. 16), barely half as broad as depth of postpedicel. When viewed anteriorly (Fig. 11), fronto-orbital plates predominantly black not very densely greyish dusted; frontal vitta dark rustbrown with a reddish tinge and thinly greyish dusted; frontal triangle and ocellar tubercle more blackish and slightly shiny; parafacial, peristomal area and anterior part of gena densely and face somewhat less whitishgreyish dusted. Lateral part of gena dark grey with a reddish-brown shimmer and, at certain angles of viewing, with white dusting; the lower margin dark brown somewhat contrasting to the upper surface. Ground colour of antennae ochre to brown, pedicel somewhat shiny with a yellowish shimmer at certain angles of viewing; postpedicel brownish, in some light conditions more or less grey dusted. Postpedicel about three times as long as broad and about 2.3 times as long as pedicel. Arista not distinctly thickened at base, yellowish-brown to brown, longest hairs of arista twice as long as depth of postpedicel. Anterior part of fronto-orbital plate with three well developed setae and one or two small interstitial hairs; the most anterior seta strong and almost twice as long as the second seta; the third seta somewhat longer than the second, on the upper half at about the level of anterior ocellus a strong long reclinate orbital seta, and another somewhat shorter orbital seta, somewhat below. An irregular row of proclinate setulae between eye margin and frontal and orbital setae, respectively. Facial ridge without visible small setulae. Vibrissal setae strong and approximately twice as long as the longest surrounding peristomal setae. Lower surface of gena and post-occipital surface dark blackish-grey, with dark seta-like hairs. Proboscis not very long and not conspicuously enlarged, prementum not bulbous, glossy brown, length of labella clearly longer than maximal depth of proboscis; palpus brownish, longer than prementum.

Thorax (Figs 1, 20). Ground-colour yellow to dark brown. Mesonotum (Fig. 20) predominantly shiny, the surface extending from anterior presutural margin to scutellar suture and between the posthumeral and intraalar setae of each body side shiny dark brown, at some viewing angles sparsely dusted; when viewed from posterior, presutural part with three broad greyish-white dusted stripes narrowing towards the transverse suture and exceeding the suture slightly. The lateral surface of mesonotum including postpronotal lobe, notopleuron and scutellum and all lateral pleura, shiny yellow (Fig. 1), in certain light conditions sparsely white dusted. Anterior and posterior spiracle strikingly yellow. Prosternum yellow. Dorsocentrals 2+3; anterior notopleural seta longer than posterior seta; prealar seta distinct, as strong as posterior notopleural seta. Greater ampulla with some black setulae. Anepisternals $1+4-5$ setae; the setae of posterior row of varying length but distinctly longer than surrounding interstitial hairs. Lateral surface of scutellum with few setulae, limited to the very anterior part, posterior lateral surface and margin to ventral surface bare.

Wing (Figs 1, 6). Membrane with a weak yellowish shimmer. Tegula and basicosta yellow, veins in basal half of wing yellowish and somewhat darker towards distal part of wing. Costal spine small, about twice as long as neighbouring bristles. Radial node and basal part of vein $\mathrm{R} 4+5$ dorsally bare, ventrally with a row of long setulae up to midway to cross-vein r-m. Both calypters (Fig. 6) brownish transparent, margin of lower calypter without a dark frame, of upper calypter with a conspicuously dark frame, lower calypter about twice as long as upper calypter.

Legs (Fig. 1). Coxae, trochanters, femora, tibiae and tarsi yellow. Fore legs missing. Mid femur preapically with a short anterodorsal, one almost dorsal and two posterior to posterodorsal setae. Hind femur with complete row of strong anterodorsal setae barely as long as depth of femur at point of insertion; in the apical third, three or four distinct anteroventral setae and in basal third one or two anteroventral and posteroventral seta-like hairs, somewhat longer than the surrounding hairs, preapically two strong posterodorsal to dorsal setae. Hind tibia at middle third with one strong anterodorsal seta, almost twice as long as diameter of tibia and two much weaker anteroventral setae, barely as long as diameter of tibia.

Abdomen. Dorsal surface of tergites shiny brown to dark brown, barely dusted. Anterior part of syntergite $1+2$, apical half of tergite five and lateral and ventral parts of tergites yellow. Tergites 3 and 4 with some moderately long marginals; tergite 5 with some discals and a row of marginals. Sternites yellow. 


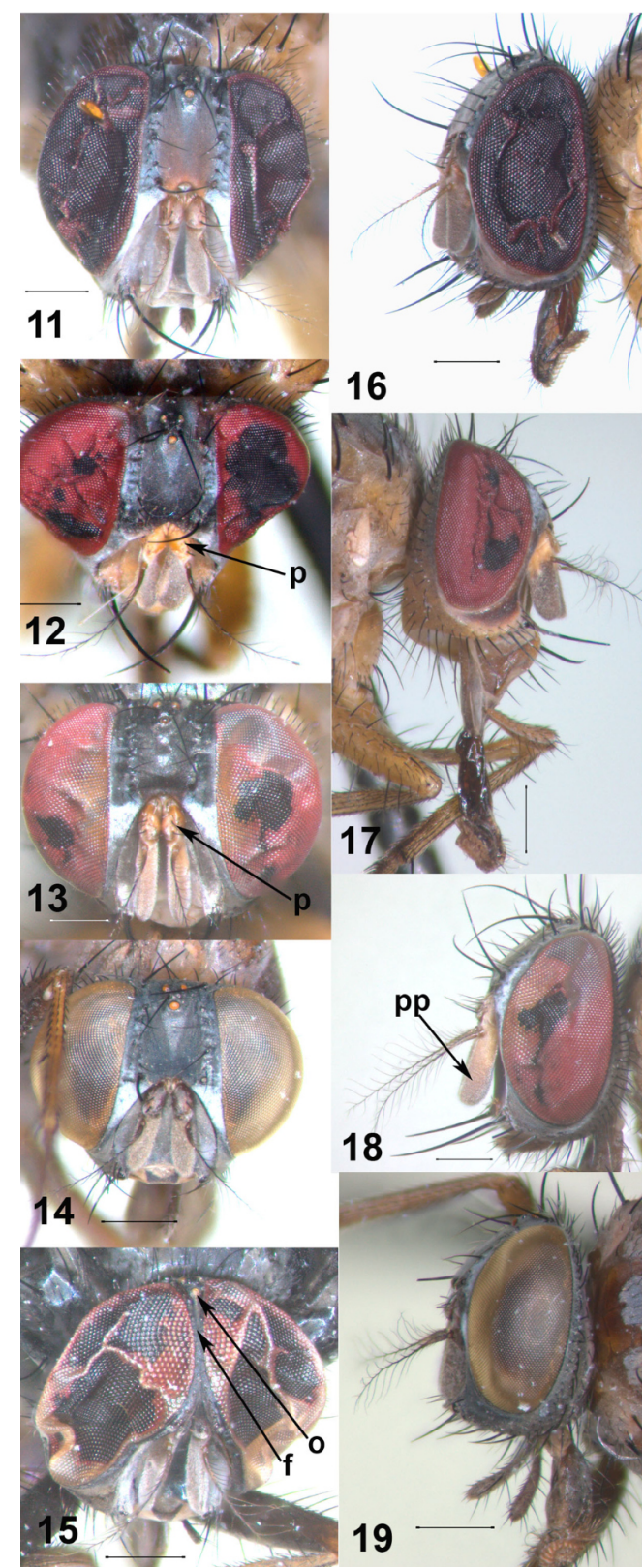

Figs 11-15. Anterior view of the holotypes of the new species of Dichaetomyia: (11) D. analama sp. n.; (12) D. necoa sp. n., p = strikingly yellow pedicel; (13) D. amboha sp. n., p = yellowish-orange pedicel; (14) $D$. tantelya sp. n.; (15) $D$. blackia $\mathrm{sp} . \mathrm{n} . \mathrm{f}=$ frons about as wide as diameter of anterior ocellus $=$ o. Figs 16-19. Side view of heads of the female holotypes of Dichaetomyia: (16) D. analama sp. n.; (17) D. necoa sp. n.; (18) D. amboha sp. n., pp = yellowish-ochre postpedicel, at least 3.5 times as long as deep; (19) D. tantelya sp. n., + paratype. (figures $11-19$ bar: $0.5 \mathrm{~mm}$ ).

Measurements. Length of body about $6 \mathrm{~mm}$; length of wing about $6.3 \mathrm{~mm}$.

Male not known.
Diagnosis: Using the key to the Madagascan species of the genus Dichaetomyia (Couri et al. 2006), the new species runs to couplet 4 , not matching one of the two options listed. On the one side, Dichaetomyia analama sp. n. does not correspond to the description of Dichaetomyia ovata (Stein, 1918), which is almost completely matt yellow coloured including the postpedicel. Whereas, the body colour of D. analama is predominantly shiny yellow, apart from the shiny dark brown surface of the mesonotum (Figs 1,20) and the equally brown-coloured dorsal surfaces of the tergites. In addition, the postpedicel of $D$. analama is predominantly brownish (Figs 11, 16). On the other side, the new species differs from the mainly brownish coloured $D i$ chaetomyia colorata Couri, Pont \& Penny, 2006 by the conspicuously uniformly yellow pleura of the thorax, the completely yellow lateral parts of tergites and the strikingly yellow legs (Fig. 1).

Dichaetomyia (Panaga) necoa sp. n. (Figs 3, 7, 12, 17, 21)

Material examined: $q$ holotype from "C Madagascar, Ambohitantely Spec. Res., S18 $11^{\circ} 43.3^{\prime \prime E} 47^{\circ} 17^{\prime} 17.7^{\prime \prime}$, $1630 \mathrm{~m}, 26 .-28 . i .2016 " .2$ ㅇ 9 paratypes from the same locality and date but with slightly different coordinates and altitude above sea level: S18 $11^{\prime} 51.7^{\prime \prime E} 47^{\circ} 17^{\prime} 0.6^{\prime \prime}$; $1604 \mathrm{~m}$ a.s.l. The left fore leg and the right fore tarsi of one paratype fell off during preparation and were transferred into a gelatine capsule which was then attached at the staging pin; the mid leg of the other paratype fell off and was preserved in ethanol for determination of DNA sequences (vial no. M6). The holotype will be deposited in the Entomological Department of the Moravian Museum, Brno, CZ and both paratypes are in the entomological collection of IBER.

Etymology: The name of the species necoa is a feminine adjective and refers, strongly modified, to the result of the first examination: "ne (= not) colorata" plus the first two and the last letter from colorata.

Description (female) [see also "Additions to the descriptions" p. 66]: Head (Figs 12, 17). Ground-colour yellow-orange with more or less dark areas. Frons at vertex about 0.26 times as wide as maximum width of head, slightly dilated towards anterior margin; at level of anterior ocellus about 3.6 times as wide as the distance between the outer margins of posterior ocelli, and at anterior margin above lunule -4.1 times as wide. Fronto-orbital plate at narrowest point about 1.5 
times as wide as anterior ocellus. Frontal triangle slender, anterior tip reaching barely the level of second anterior fronto-orbital seta. Parafacial at level of antenna basis distinctly wider than half depth of postpedicel and at the lower end about as wide as anterior ocellus. Genal depth below lowest eye margin (Fig. 17) about as wide as depth of postpedicel. When viewed anteriorly (Fig. 12), fronto-orbital plate predominantly black with sparse whitish-grey dusting, frontal vitta of the two paratypes contrasting yellowish-orange, more whitish dusted in one female; holotype with a dark frontal vitta slightly greyish-white dusted and concolorous with the fronto-orbital plate, frontal triangle concolorous with frontal vitta, ocellar tubercle blackish. Parafacial and anterior part of gena yellow with some whitish dusting, parafacial and anterior surface of gena of holotype predominantly brownish, densely white dusted; face yellow with greyish-white dusting. Lateral part of gena yellow, the upper half reddish in two females and blackish and white dusted in holotype. Basal antennal segments (Figs 12, 17) and basis of postpedicel up to the insertion of arista conspicuously yellowish, contrasting to the dark brown and greyish dusted apical two thirds of postpedicel. Postpedicel at most three times as long as deep and about 2.5 times as long as pedicel. Arista uniformly dark brown, longest hairs of arista about 1.3 times as long as depth of postpedicel. Anterior half of fronto-orbital plate with two setae, the most anterior seta strong and long, the upper one distinctly smaller, in addition two smaller interstitial seta-like hairs, one of which at about midway of frons. At about the level of anterior ocellus, a strong reclinate orbital seta and another reclinate orbital seta slightly below, at most half as long as the upper seta. An irregular row of proclinate setulae between eye margin and setae. Fascial ridge at basal third with a few very small setulae along the suture to parafacial, no other small setulae visible on facial ridge. Vibrissal seta strong and approximately twice as long as the longest surrounding peristomal setae. Lateral surface of gena and lower occipital part predominantly yellowish. Proboscis (Fig. 17) long, prementum not bulbous, glossy brown, length of labella slightly longer than depth of proboscis; palpus yellow, shorter than prementum.

Thorax (Figs 3, 21). Ground-colour mainly brownish. Mesonotum (Fig. 21) predominantly dark brown, the central part almost blackish with reddish-brown shimmer, depending on viewing angle shiny or whitish dusted. Posteriorly of the brown transverse suture the supra-alar area of mesonotum, bordered by the intra- alar setae, yellow or reddish-brown. When viewed from posteriorly presutural part of scutum with a broad median greyish-white dusted stripe narrowing towards the transverse suture, shortly interrupted at the suture and continued behind the suture as a much narrower, whitish stripe almost reaching the scutellar suture. In addition, a paramedian whitish-greyish stripe (along outside of each row of dorsocentrals) reaching the transverse suture and extending to a greyish-white transverse band along the suture. Scutellum (Fig. 21) uniformly yellow, strikingly contrasting to the dark parts of mesonotum. Postpronotum, anterior part of notopleuron and adjacent part of anepisternum, including the area around anterior spiracle, strikingly yellow. Lateral pleura brown (Fig. 3), at least slightly greyishwhite dusted independently of viewing angle. Anterior and posterior spiracle yellow. Prosternum yellow. Dorsocentrals $2+3$; the outer postpronotal seta almost twice as long as the inner seta; the anterior notopleural seta longer than the posterior; pre-alar seta distinct, almost as long as posterior notopleural seta. Greater ampulla with some strong setulae. Anepisternal setae $1+4-5$; the posterior setae strong and of varying length, surrounded by very few rather short interstitial seta-like hairs. Lateral surface of scutellum, including the margin to the ventral surface, with few setulae.

Wing (Figs 3, 7). Membrane with a brownish shimmer. Tegula and basicosta yellow or ochre, veins brown. Costal spine small, about twice as long as neighbouring bristles. Radial node and basal part of vein R4+5 dorsally at most with one or two setulae and ventrally up to midway to cross-vein r-m with a few rather weak setulae. Both calypters (Fig. 7) transparent with a brownish tinge and contrasting dark brown frames of the margins, lower calypter almost twice as long as upper calypter.

Legs (Fig. 1). Coxae, trochanters, femora, tibiae and tarsi yellow. Fore tibia without a median posterior seta. Mid femur preapically with a short anterodorsal, one almost dorsal and two posterior to posterodorsal setae. Hind femur with a complete row of strong anterodorsal setae and in the basal two thirds with a row of anteroventrals, weak and only somewhat longer than ground hair, followed by four longer anteroventral setae in the apical third, of which the most apical setae are equal in length to the anterodorsal setae; preapically two strong posterodorsal to dorsal setae. Hind tibia in middle third with one strong anterodorsal seta longer than diameter of tibia and one weaker anteroventral seta barely as long as diameter of tibia. 


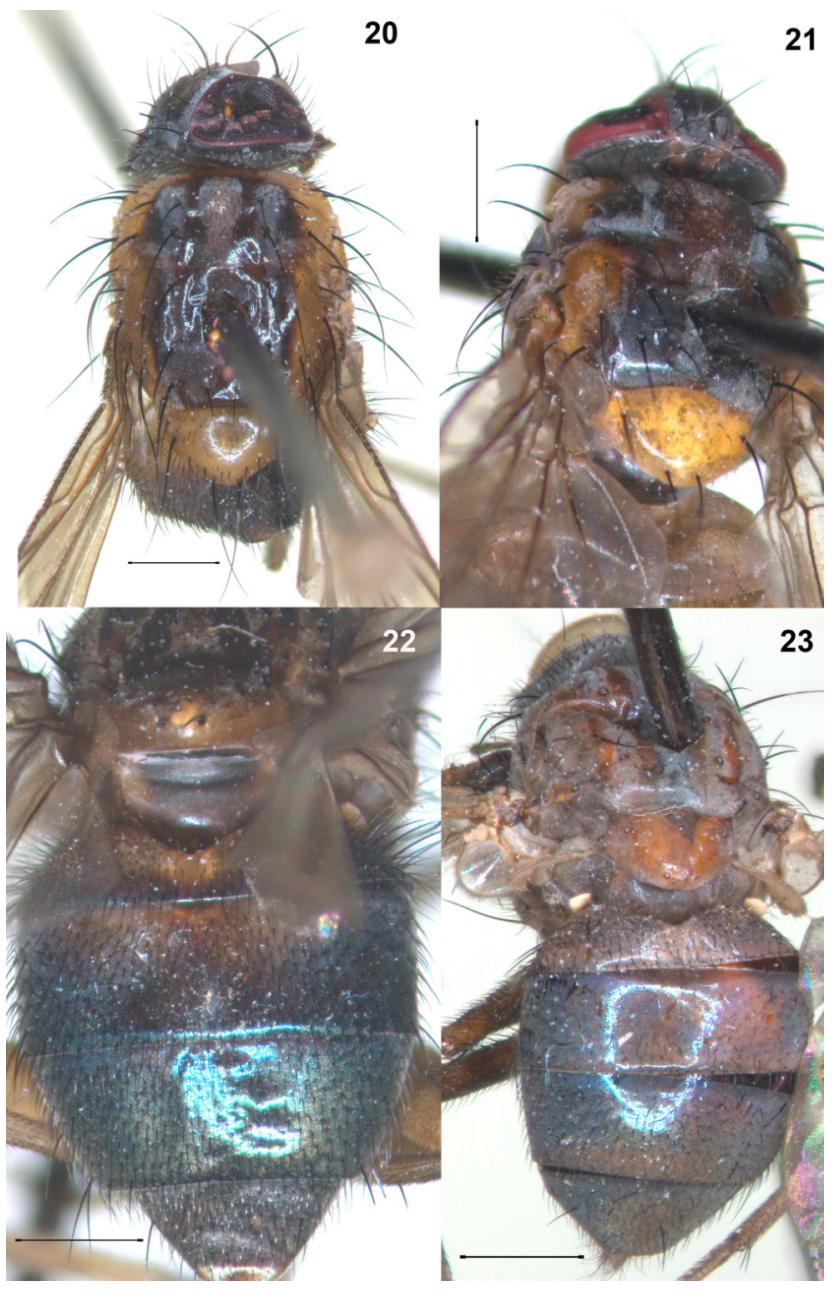

Figs 20-23. Dorsal view of mesonotum and/or abdomen of the female holotypes of the new species of Dichaetomyia: (20) D. analama sp. n., predominantly shiny brown mesonotum with yellow lateral parts of mesonotum, adjacent pleura and of scutellum; (21) D. necoa sp. n., thorax with mesonotum and contrasting yellow scutellum; (22) $D$. amboha sp. n., scutellum with a yellow apical tip; abdomen with yellowish markings on anterior part of syntergite $1+2$ and close to the anterior margin of tergite 3 , the abdomen is in normal light conditions usually predominantly shiny dark brownish to blackish, when exposed to photographic illumination with a bluish shine; (23) D. tantelya sp. n., mesonotum distinctly reddish brown marked and densely dusted at some viewing angles; abdomen in normal light conditions without a distinct pattern, colouration varying between reddish-brown and dark brown and shiny or slightly dusted, depending on the point of viewing, in photographic light conditions the abdomen appears partially shiny bluish. (Figures 20-23 bar: $1 \mathrm{~mm}$ ).

Abdomen. Shiny brown to dark brown; the abdomen of each of the three females is stretched and the yellowish intersegmental membrane and the anterior parts of the tergites which are usually covered by the posterior margins of the anterior tergites are visible, showing a yellow band between the dorsally brown tergites. Anterior half of syntergite $1+2$ dorsally and ventrally predominantly yellow, posterior part dorsally yellowish-brown laterally and ventrally yellow; tergites 3 to 5 dorsally brown, laterally on the upper surface brown changing to predominantly yellow in the ventral parts of tergites. Apical third to half of dorsal surface of tergite 5 yellow. Tergite 4 with a row of moderately long marginals, tergite 5 with some discals and a row of marginals. Colour of sternites varying between yellow to pale brownish, shiny at some points of viewing.

Measurements. Length of body about $7 \mathrm{~mm}$; length of wing about $6.8 \mathrm{~mm}$.

Male not known.

Diagnosis: The specimens of Dichaetomyia necoa sp. n. run in the key to D. colorata and in updated couplets of the same key (Zielke 2020) to couplet 5a with $D$. colorata and $D$. necolorata Zielke, 2020. The legs of $D$. colorata and of the similar species of $D$. necolorata are light brownish to brown, the antennae are predominantly brown, the postpedicel are at least 3.5 times as long as deep and the palpi are brownish and about as long as or longer than prementum. Dichaetomyia necoa, however, is marked by distinctly yellow legs including coxae and trochanters, the basal antennal segments including the basal part of postpedicel are conspicuously yellow, contrasting to the dark apical part of postpedicel. The latter is barely three times as long as deep, the palpi are predominantly yellow and barely as long as prementum.

\section{Dichaetomyia amboha sp. n. (Figs 2, 9, 13, 18, 22)}

Material examined: $q$ holotype from "C Madagascar, Ambohitantely Spec. Res., S18 $11^{\prime} 51.7^{\prime \prime E} 47^{\circ} 17^{\prime} 0.6^{\prime}$, $1604 \mathrm{~m}, 26 .-28.1 .2016$ ". 1 9 paratype same label as holotype, the left mid leg of the paratype fell off during preparation and was preserved (vial no. M5) for DNA analysis; 6 q $q$ paratypes from "C Madagascar, Ambohitantely Spec. Res., S18¹1'44,5"E47¹7'14,9", 1617 $\mathrm{m}, 26 .-28.1 .2016$, loc. coll." Two of the paratypes lost the left mid and the two fore legs during preparation, the extremities were preserved in ethanol for DNA analysis (vial numbers M18 and M33 respectively). Another $q$ paratype from "C Madagascar, Ambohitantely Spec. Res., S18 $11^{\prime} 51^{\prime \prime E} 47^{\circ} 16^{\prime} 59^{\prime \prime}, 1585 \mathrm{~m}$, 5.-8.i.2017, Flight Intercept. Trap." The holotype and 
three paratypes will be deposited in the Entomological Department of the Moravian Museum, Brno, CZ and four paratypes remain in the entomological collection of IBER.

Etymology: The name of the species amboha is a feminine adjective and derives somewhat modified from the name of the Ambohitantely Reserve on Madagascar, the locality where the specimens of this new species were collected.

Description (female) [see also "Additions to the descriptions" p. 66]: Head (Figs 13, 18). Ground-colour dark, partially densely greyish-white dusted. Eyes of a few specimens with facets close to frons, somewhat larger than the facets of lateral areas. Frons at vertex about 0.33 times as wide as maximum width of head, parallel-sided, at level of anterior ocellus and at anterior margin of frons about 3.8 times as wide as distance between the outer margins of posterior ocelli. Fronto-orbital plate at narrowest point about twice as broad as anterior ocellus. Frontal triangle slender, anterior tip reaching about the level of second anterior pair of fronto-orbital setae. Parafacial at level of antenna basis slightly wider than depth of postpedicel and at the lower end as wide as anterior ocellus. Genal depth below lowest eye margin, 0.7 times as broad as depth of postpedicel (Fig. 18). When viewed from anterior side (Fig. 13) upper half of head blackish, while fronto-orbital plate, frontal vitta with frontal triangle and ocellar tubercle black, depending on viewing angle shiny or somewhat greyish dusted; lower part of head with parafacial, face, peristomal area and anterior part of gena predominantly more or less silver-white dusted. Basal segments of antenna and basal half of postpedicel predominantly yellowish, apical half of postpedicel ochre to brown (Fig. 18). Postpedicel at least 3.5 times as long as deep and as long as pedicel. Arista brownish, longest hairs of arista about twice as long as depth of postpedicel. Anterior half of fronto-orbital plate with three or four setae, the most anterior seta strong and about twice as long as the upper setae, a few smaller interstitial hairs between the setae, at the level of anterior ocellus a strong reclinate orbital seta with another somewhat shorter orbital seta slightly below. An irregular row of small proclinate setulae between eye margin and fronto-orbital and orbital setae along the entire length of frons. Facial ridge with several small setulae, clearly visible when viewed from certain angles. Vibrissal seta strong and at least twice as long as the longest surrounding peristomal setae. Lower surface of gena and post-occipital surface brown to dark, slightly greyish dusted. Proboscis short, conspicuously dilated towards labella, prementum short, ochre to brown, and slightly whitish-grey dusted; labella about as long as prementum, and slightly longer than largest depth of proboscis; palpus yellowish or brown, distinctly longer than prementum.

Thorax (figs 2, 22). Ground-colour mainly brownish to dark brown. The surface of the mesonotum between the rows of dorsocentral setae predominantly dark brown, depending on viewing angle slightly shiny or greyish-white dusted, the postsutural area outside the rows of the dorsocentral setae brown or reddishbrown, varying in intensity and extent in the individual females. From posterior view presutural part of mesonotum with a broad middle grey-white dusted stripe that reaches the transverse suture and continues in the postsutural part of the mesonotum to the scutellar suture, but is abruptly post-sutural reduced to a maximum of one third of its original width; a paramedian grey-white dusted stripe, which is somewhat widened on the anterior presutural part and extends along each row of the dorsocentral setae, shortly behind the transverse suture on the lateral red-brown postsutural surface, the stripe widens to a greyish-white dusted area, which reaches the posterior postsutural dorsocentral seta, in addition a distinct longitudinal dark stripe outside of the postsutural dorsocentral setae extending to the level of the posterior dorsocentral seta. Dorsal surface of scutellum dark brown and slightly shiny, lateral and ventral surface and apical tip contrasting yellow (Fig. 22). Postpronotum and in most specimens also notopleuron conspicuously yellow (Fig. 2), in few paratypes notopleuron more brownish-yellow or only brownish. Lateral pleura pale-brown to brown, depending on viewing angle more or less greyish dusted (Fig. 2). Anterior spiracle strikingly yellow, posterior more yellowish-brown. Prosternum yellow. Dorsocentrals $2+2$; the outer postpronotal seta distinctly longer than the inner seta; anterior notopleural seta much longer than the posterior; pre-alar seta distinct, about half as long as posterior notopleural seta; the intra-alar setae relatively short. Greater ampulla without distinct setulae. Anepisternal setae 1+4-5, posterior setae of varying length, surrounded by numerous interstitial setalike hairs, some of which almost as long as the shortest seta. Basal and preapical setae of scutellum barely longer than the long ground-hair; lower half of lateral surface of scutellum including the margin to the ventral surface bare. 
Wing (Figs 2, 9). Membrane with a brownish shimmer. Tegula and basicosta predominantly brownish, veins brown. Costal spine small, about twice as long as neighbouring bristles. Radial node and basal part of vein $\mathrm{R} 4+5$ dorsally and ventrally with a few setulae. Both calypters transparent, in general without dark frames (Fig. 9), only in certain light conditions with contrasting dark brown margins, lower calypter about twice as long as upper calypter.

Legs (Fig. 2). Coxae, trochanters, femora, tibiae and tarsi yellow. Fore tibia with a median posterior seta longer than the diameter of tibia. Mid femur preapically with a short anterodorsal and three or four strong posterior to posterodorsal and dorsal setae. Hind femur with complete row of strong anterodorsal setae barely as long as depth of femur at the point of insertion; at the apical third three or four anteroventral setae longer than the anterodorsal setae, preapically two strong posterodorsal to dorsal setae. Hind tibia in middle third with one strong anterodorsal seta longer than diameter of tibia and two or three weaker anteroventral setae, barely as long as diameter of tibia.

Abdomen (Figs 2, 22). When viewed dorsally ground-colour predominantly uniformly dark brown and shiny, in some light conditions tergites 3 to 5 irregularly greyish dusted; anterior half of syntergite $1+2$ dorsally and ventrally yellowish coloured, posterior part of syntergite dorsally at middle part somewhat yellowish, dorsolateral and sides shiny dark brown. Anterior dorsal half of tergite 3 with more or less well developed yellowish dorsal areas (Fig. 22). When viewed from posterior, tergites predominantly shiny dark and in certain light conditions with a distinct brownish-blue shimmer. Tergite 5 in some specimens marked by a narrow yellow apical margin (Fig. 22); lateral and ventral parts of tergites about concolorous with dorsal surface (Fig. 2). Tergite 4 laterally with few marginal and discal setae, tergite 5 with some discals and a row of marginals. Sternites varying between yellow to pale brownish

Measurements. Length of body about $8 \mathrm{~mm}$; length of wing about $8.5 \mathrm{~mm}$.

Male not known.

Diagnosis: The females of Dichaetomyia amboha sp. n. are similar to the specimens of Dichaetomyia tricolorata Couri, Pont \& Penny, 2006. Both species differ, however, in addition to body length $(8 \mathrm{~mm}$ vs 6-6.4 mm), by the following taxonomic features: The postpedicel of females of $D$. tricolorata is at most three times as long as deep and only the pedicel is yel- lowish-brown, whereas the postpedices predominantly brown. The abdomen is dull greyish-brown coloured with greyish dusting, tergites 3 to 5 with hints of not clearly defined brown spots. In D. amboha, however, the postpedicel is at least 3.5 times as long as deep (Fig. 18). Not only the pedicel, but also the postpedicel is usually predominantly yellowish-orange coloured. The abdomen is predominantly shiny dark brown to blackish without faint brown patches on tergites 3 to 5 (Fig. 22).

\section{Dichaetomyia blackia n. sp. (Figs 4, 8, 15)}

Material examined: $\widehat{\delta}$ holotype from "N Madagascar, Ankarana N. P., S12 ${ }^{\circ}$ 57'E4907', 987 m, 23.-25.i.2016, Flight Intercept. Trap in dark forest". The male's head has shrunk significantly and the specimen is lacking the mid legs and some of the major setae. However, the important taxonomic features of the head and most scars of the lost setae are clearly visible. Due to the distinctive species-specific characteristics, the differentiation and description of the new species was not impaired despite the abovementioned deficiencies. The holotype will be deposited in the Entomological Department of the Moravian Museum, Brno, CZ.

Etymology: The species' name is an adjective in feminine case, modified from "black", the predominant colour of the holotype.

Description (male): Head (Fig. 15). Ground-colour dark brown to black, at some points of viewing sparsely brownish-grey dusted. Eyes large, practically without hairs, facets next to frons distinctly larger than facets on the outer side of eye. Frons at the narrowest point as wide as diameter of anterior ocellus (Fig. 15), fronto-orbital plates at that point half as broad as anterior ocellus and touching along the middle third of frons, separated anteriorly by a short triangular-shaped and in upper part of frons by a line-shaped frontal vitta. Parafacial predominantly parallel-sided, tapering at the lower third, at level of insertion of arista to postpedicel about as broad as anterior ocellus. In profile mouth margin in line with profrons. Genal depth below lowest eye margin as broad as anterior ocellus. When viewed from the anterior side, fronto-orbital plate black, frontal vitta, where available, greyish dusted and parafacial, peristomal area and anterior surface of gena dark with some grey dusting. Antennal segments uniformly dark and at certain viewing angles sparsely greyish dusted. Postpedicel about 3.5 times as long as deep and 
also about 3.5 times as long as pedicel. Arista dark brown, approximately twice as long as length of postpedicel, longest dorsal hairs of arista longer than twice the depth of postpedicel. Fronto-orbital plate with scars of three or four distinct setae on anterior quarter and with very few interstitial smaller hairs, at level directly below the ocellar tubercle a distinct scar of a strong orbital seta and shortly below a strong reclinate setula. Parafacial bare. Facial ridge in anterior third with a few setulae along the margin adjacent to gena and lower part of parafacial. Scars of vibrissal setae very strong, the surrounding peristomal setae not very long. Lower surface of gena and post-occipital surface dark with sparse brownish-grey dusting and black seta-like hairs. Proboscis short, dark brown, prementum dark brown not shiny, slightly dusted; labella strikingly large, about twice as long as maximal depth of proboscis; palpus dark brown almost black, slender and longer than prementum.

Thorax (Fig. 4). Ground-colour uniformly deep dark brown to blackish. Mesonotum predominantly shiny. When viewed from the posterior or anterior side, the presutural part of mesonotum with two greyishwhite stripes along the dorsocentral setae reaching the suture; from certain viewing angles the presutural part of mesonotum with sparse greyish dusting. Posterior part of mesonotum black and predominantly shiny, scutellum concolorous with mesonotum but somewhat more brownish. Pleura all dark brown to black (Fig. 4), depending on point of viewing uniformly thinly greyish dusted or shiny. Anterior and posterior spiracle dark, posterior one with some black setulae at lower margin. Dorsocentrals 2+2; acrostichals $0+1$ about half as long as the posterior dorsocentral seta; two postpronotal setae, the outer one distinctly longer and stronger; two notopleural setae, anterior one longer, notopleuron with a few small black hairs in posterior half; pre-alar seta barely half as long as posterior notopleural seta; two intra-alar setae. Greater ampulla without distinct setulae, postalar declivity and suprasquamal ridge bare. Prosternum dark and haired; anepimeron with a tuft of setulae above and some scattered seta-like hairs on the posterior surface. Proepimeral area and katepimeron bare; meron with a few very fine hairs, longer than setulae, predominantly above hind coxa but on the left body side also below the posterior spiracle. Katepisternals $1+2$, the lower one distinctly closer to the posterior than to the anterior seta. Anepisternals $1+5$, the setae of the posterior row strong and varying in length, about twice as long as the adjacent interstitial seta-like hairs. Scutellum with a pair each of strong apical and strong lateral setae, basal seta and preapical seta distinctly shorter, only upper half of lateral surface with few setulae, lower half and margin to ventral surface bare.

Wing (Figs 4, 8). Membrane hyaline with a distinct yellowish-brown shimmer, cross-veins and surrounding membrane not infuscate. Tegula and basicosta dark, veins yellowish-brown. Costal spine not distinct. Radial node dorsally bare, ventrally with at most three setulae, basal part of vein R $4+5$ dorsally and ventrally bare. Vein $\mathrm{M}$ somewhat diverging from vein $\mathrm{R} 4+5$, but slightly curved forward to $\mathrm{R} 4+5$ before reaching wing margin. Cross-vein r-m clearly basad of the point where vein R1 enters costa; distal cross-vein dm-cu sinuous and oblique. Both calypters (Fig. 8) brownish transparent, margin of upper calypter brownish, margin of lower calypter conspicuously dark brown; lower calypter almost twice as long as upper calypter. Knob of haltere brown, basis of stem dark yellow.

Legs (Fig. 4). Coxae, trochanters and femora brown, tibiae and tarsi predominantly yellow. Pulvilli and claws well developed, but not as long as the corresponding tarsomeres. Fore femur with rows of posterodorsal, posterior and posteroventral setae, the posterodorsal and posterior setae at least as long as depth of femur at the point of insertion, posteroventral setae clearly longer than depth of femur. Fore tibia with a distinct but not conspicuously long median posterior seta. Mid legs missing. Hind coxa bare on posterior surface. Hind femur with complete row of strong anterodorsal setae, a complete row each of anteroventral and posteroventral setae, the setae of both ventral rows in the basal half about half as long (for anteroventral setae) or about one third as long (posteroventral setae) as the depth of femur at point of insertion and in the apical part, about as long as depth of femur; preapically two strong posterodorsal to dorsal setae. Hind tibia without distinct posterodorsal seta, on middle third one anterodorsal and two or three anteroventral setae, all about as long as diameter of tibia.

Abdomen (Fig. 4). Uniformly glossy dark brown, almost black, without specific pattern; when viewed directly posteriorly, partly sparsely brownish dusted. Tergite 3 with a few strong marginal setae laterally, tergite 4 with several strong marginals and a few strong discals laterally, tergite 5 with some discals and marginals. Sternites brown, margin of sternite 1 haired.

Male genitalia. Hypopygium not pronounced. The species is clearly distinguished from similar species of 
the genus by other taxonomic characters, the determination of the species is not based on characters of genitalia. Therefore, it was deemed wiser to refrain from extracting the hypopygium to avoid inflicting damage on the only hitherto available specimen.

Measurements. Length of body about $5.5 \mathrm{~mm}$; length of wing about $6 \mathrm{~mm}$.

Female not known.

Diagnosis: Dichaetomyia blackia $\mathrm{n}$. sp. runs in the key to Dichaetomyia nigra Couri, Pont \& Penny, 2006. However, the mesonotum of $D$. nigra is dark browncoloured with grey pollinosity, there are two black stripes inside the rows of dorsocentral setae; postpronotum is yellowish-brown; anterior spiracle white; trochanters and femora are brownish-yellow or yellow; abdomen is dark brown with some grey pollinosity. Postpedicel is about 2.6 times as long as pedicel. Meron without fine hairs in lower half; wing vein R4 +5 with setulae dorsally on radial node and at base of vein; hind femur with three or four anteroventral setae on apical third. In contrast, the mesonotum and the pleura of D. blackia are uniformly shiny dark-brown to blackish, without any yellowish pattern or surfaces; the anterior spiracle is dark; trochanters and femora are brown; abdomen is shiny black. The postpedicel is at least three times as long as pedicel. Distinct fine hairs are present in the lower half of the meron; vein $\mathrm{R} 4+5$ is dorsally without setulae and the hind femur is marked by a complete row of anteroventral setae and in apical third with a row of strong posteroventral setae.

\section{Dichaetomyia tantelya $\mathrm{n}$. sp. (Figs 5, 10, 14, 19, 23)}

Material examined: $q$ holotype and $q$ paratype from: "Madagascar, Ambohitantely Spec. Res., S18 11 '54,9"E4716'52,6", 1580 m, 20.-25.xi.2011, local coll." Holotype and paratype are lacking some major setae, however the scars of the lost setae are clearly visible. The female paratype is lacking the right mid leg. The holotype will be deposited in the Entomological Department of the Moravian Museum, Brno, $\mathrm{CZ}$ and the paratype is deposited in the entomological collection of IBER.

Etymology: The name of the species is an adjective in feminine case and derives from the second half of the name of the area where the specimens were collected.

Description (female) [see also "Additions to the descriptions" p. 66]: Head (Figs 14, 19). Ground-col- our dark, partially greyish-white dusted. Frons at vertex about 0.27 times as wide as maximum width of head, somewhat dilated towards the anterior margin, at level of anterior ocellus about 3.2 times and at anterior margin about four times as wide as the distance between the outer margins of posterior ocelli (Fig. 14). Fronto-orbital plate at level of anterior ocellus about 0.7 times as wide as distance between outer margins of posterior ocelli. Ocellar triangle slender, anterior tip almost but not quite reaching anterior margin of frons. Parafacial at level of antenna basis slightly wider than depth of postpedicel and at the lower end not much wider than anterior ocellus. Genal depth below lowest eye margin almost as wide as depth of postpedicel (Fig. 19). When viewed from the anterior side, fronto-orbital plate and parafacial predominantly greyish-white dusted; frontal vitta, frontal triangle and ocellar tubercle black with sparse grey dusting; frontal triangle at some viewing angles somewhat shiny; face greyish dusted, peristomal area and anterior part of gena predominantly dark grey with sparse pale dusting. Antennal segments uniformly brown, postpedicel from some points of viewing greyish-brown dusted. Postpedicel three times as long as deep and about 2.3 times as long as pedicel. Arista at base somewhat bulbous thickened, brown; longest hairs of arista about 1.6 times as long as depth of postpedicel. Anterior half of fronto-orbital plate with three setae and with one or two very small interstitial setulae: the most anterior seta strong and long, the upper setae distinctly shorter, at about midway a small proclinate seta and on the upper half of fronto-orbital plate at the level of anterior ocellus a strong reclinate orbital seta, another, somewhat shorter, orbital seta slightly below; an irregular row of setulae between eye margin and orbital and frontal setae. Facial ridge with few barely recognisable setulae. Vibrissal setae strong and at least twice as long as the longest surrounding peristomal setae. Upper half of lateral surface of gena bare, lower surface and post-occipital surface dark, greyish dusted and with dark setalike hairs. Proboscis short, prementum rather broad not very deep, brown, dusted, length of labella distinctly longer than depth of proboscis; palpus dark brown, longer than prementum.

Thorax (Figs 5, 23). Ground-colour brownish. Mesonotum brownish-yellow, depending on angle of viewing more shiny or predominantly whitish-grey dusted; when viewed directly from posterior presutural part of mesonotum with a median vitta reaching scutellar suture, densely whitish-grey dusted in the presutural 
part and gradually fading to a dark greyish ground-colour at the posterior half of postsutural part; a paramedian whitish-grey stripe along each row of dorsocentrals reaching the scutellar suture, dilated at the anterior presutural part of mesonotum and slightly narrowing before and shortly after the transverse suture; the surface along the white dusted stripes yellowish-brown with sparse dusting only. The raised part of postpronotum predominantly yellow, the lower basal part yellowish-brown or greyish dusted. Scutellum predominantly yellow with sparse dusting and in holotype with a dark brown triangular-shaped patch (Fig. 23), which is not present in the paratype. All pleura (Fig. 5) brownish or grey, depending on viewing angle more or less greyish dusted. Anterior spiracle yellowish-grey, posterior spiracle brownish. Prosternum dark brown. Dorsocentrals $2+2$; outer postpronotal seta almost twice as long as the inner seta; anterior notopleural seta much longer than the posterior; pre-alar seta distinct, about half as long as posterior notopleural seta. Greater ampulla without distinct setulae. Anepisternal setae $1+5$, posterior setae of varying length, surrounded by several rather short interstitial seta-like hairs. Lateral surface of scutellum including the margin to the ventral surface with a few setulae.

Wing (Figs 5, 10). Membrane with a distinct brownish shimmer. Tegula and basicosta pale brown, veins brown. Costal spine prominent, about three times as long as adjacent bristles. Radial node dorsally and ventrally with few setulae, basal part of vein $\mathrm{R} 4+5$ dorsally bare and ventrally with a row of distinct setae reaching at least midway to cross-vein $r-m$. Cross-vein $r-m$ almost at the same level where vein R1 enters costa; distal cross-vein dm-cu almost straight and at a right angle with vein $M$. Both calypters yellowishwhitish transparent margin with yellowish-brown frame (Fig. 10), lower calypter about 1.5 times as long as upper calypter.

Legs (Fig. 5). Coxae, trochanters and femora predominantly brown, tibiae and tarsi yellow. Fore tibia with a median posterior seta about 1.5 times as long as diameter of tibia. Mid femur in apical third with a row each of anteroventral and posteroventral setae, about one third as long as depth of femur at point of insertion, preapically with a short anterodorsal, one short dorsal and two distinctly longer posterior to posterodorsal setae. Hind femur with complete row of strong anterodorsal setae, ventral surface of basal half with some hairs almost half as long as depth of femur, in the apical third four anteroventral setae, the two most apical setae distinctly stronger, preapically two strong posterodorsal to dorsal setae. Hind tibia in middle third one strong anterodorsal seta longer than diameter of tibia and one slightly weaker anteroventral seta.

Abdomen (Figs 5, 23). When viewed dorsally syntergite $1+2$ and tergite 3 predominantly shiny reddishbrown to dark brown and tergites 4 and 5 mainly dark brown with a diffuse bluish-black shimmer (Fig. 23). However, the colour of the abdomen varies depending on the light conditions, the anterior tergites might be more yellowish and at some angles, lateral and ventral parts of tergites are almost uniformly dark with bluishblack reflections, in certain lighting conditions all tergites are more or less slightly greyish-brown dusted. Tergite 3 is marked by a row of short marginal setae and tergite 4 is marked by a row of long and strong marginals, tergite 5 - by a row of long discals. Sternites brown, somewhat shiny.

Measurements. Length of body about $7.5 \mathrm{~mm}$; length of wing about $7 \mathrm{~mm}$.

Male not known.

Diagnosis: The taxonomic characteristics of the new species lead in the identification key to D. tricolorata. In addition, the new species also resembles to some extent Dichaetomyia amboha, which is described above as another new species. Dichaetomyia tantelya sp. n. differs from both species by the brown coxae, trochanters, femora and evenly-coloured dark brown antennae (Fig. 5, 19), which are more or less conspicuous yellow in the other two species. In addition, the shiny reddish-brown to dark brown abdomen of $D$. tantelya differs distinctly from the matt greyish-brown abdomen of $D$. tricolorata, and it differs from the abdomen of $D$. amboha by lacking defined yellow markings on the dorsal surface of syntergite $1+2$ and tergite 3 (Figs 22, 23).

\section{Remarks}

The descriptions of four of the five new species are based on female holotypes, as the males of the new species are still unknown. However, the female types differ from related species in several respects, so that their identification as a new species and the differentiation from other species is unambiguous. New species of $D i-$ chaetomyia have already been described in the past by various authors only on the basis of existing females. The males belonging to the species were sometimes not identified until many years after the species was first de- 
scribed. For example, Dichaetomyia madagascariensis was originally described by Séguy in 1938, and Dichaetomyia harlekini as Annaria harlekini in 1972 by Zielke, on the basis of female specimens. It was only in 2006 that males of these two species were mentioned in the literature. Couri et al. (2006) reported, among other identified specimens, one male of each species found during the investigations of the Malagasy material. In addition, during the ongoing studies, two more males of D. madagascariensis were identified.

Apart from the five newly described species listed above, one male and five females of another species were identified, which led in the identification key for Malagasy species of Dichaetomyia directly to D. nigra. However, the specimens did not match most of the taxonomic features listed in the key and in the species description. It was, therefore, checked whether this species, unknown from Madagascar, is listed in the identification keys for Dichaetomyia by van Emden (1942) for Africa and von Pont (1978) for the Comoros. The taxonomic characteristics of the species did not lead to any of the members of the genus known from the Comoros Archipelago. In van Emden's key, however, the determination ended in Dichaetomyia polita polita Malloch, 1921 in couplet 17 (18). In couplet 18 (17) van Emden (1942) describes Dichaetomyia polita ugandana in an extremely short version as a new subspecies, about which he published a few more details nine years later (van Emden, 1951). The two subspecies are very similar and can only be differentiated by the colour of the femora. The specimens from Madagascar seem to agree more with $D$. polita polita than with D. polita ugandana. However, the criteria listed in van Emden's identification key are not detailed enough to definitively assign the Malagasy flies to this species. And although D. polita described by Malloch in 1921 is also the genotype of the newly described genus Dichaetomyia Malloch, 1921, the description of $D$. polita is not sufficiently differentiated. A definite assignment of the Malagasy specimens based on the species description is not possible due to the rudimentary characterisation. It can only be stated that there are no major differences between the few taxonomic features mentioned in the description and the characteristics of the examined flies.

It should also be noted that Pont (1969) renamed $D$. polita to Dichaetomyia emdeni Pont, 1969 due to an existing junior homonym, and that the other subspecies has been listed in the catalogue of Afrotropical Muscidae (Pont, 1980) as a distinct species, namely $\mathrm{Di}$ - chaetomyia ugandana van Emden, 1942. Dichaetomyia emdeni is so far only known from Kenya. If it would be confirmed that the specimens from Madagascar belong to this species, D. emdeni would be the third species of the known Malagasy fauna of Dichaetomyia, which - besides D. ovata and Dichaetomyia albivitta (Stein, 1906) - also exists outside Madagascar.

\section{Acknowledgements}

I am very grateful to the colleagues and entomological institutions named below for supporting my studies on the Muscidae from Madagascar by providing type and non-type specimens for studying and comparison: Petr Baňař, curator at the Entomological Department of the Moravian Museum, Brno (CZ); Christopher Grinter, collections manager of Entomology of Californian Academy of Sciences, San Francisco, CA/USA; Nigel Wyatt, curator of the collection of Diptera of the Department of Life Sciences of the Natural History Museum, London, UK; Kirstin Williams, chief curator of Arthropoda, KwaZulu-Natal Museum, Pietermaritzburg, South Africa; Jenny Pohl and Sven Marotzke, conservators of the Museum für Naturkunde in Berlin, D; Zoë Simmons, collections manager of Diptera and Arachnida from the Oxford University Museum of Natural History, Oxford, UK. I also wish to thank Toshko Ljubomirov, responsible for the Zoological Collection of the Institute of Biodiversity and Ecosystem Research, Sofia, Bulgaria for supporting my work on the taxonomy of the Muscidae by giving me generous access to the dipteran collection of the Institute of Biodiversity and Ecosystem Research with the Bulgarian Academy of Sciences and for providing the facilities needed for the examination of the material. My thanks are also due to two anonymous reviewers for helpful comments for the improvement of this contribution.

\section{References}

Couri S.C., Pont A.C., Penny N.D. 2006 Muscidae (Diptera) from Madagascar: Identification Keys, Descriptions of New Species, and New Records. Proceedings of the California Academy of Sciences 57: 799-923.

Gregor F., Rozkošny R., Barták M., Vaňhara J. 2002 The Muscidae (Diptera) of Central Europe. Folia 
Facultatis Scientiarum Naturalium Universitatis Masarykianae Brunensis, Biologia 107: 1-280.

Gregor F., Rozkošny R., Barták M., Vaňhara J. 2016 Manual of Central European Muscidae (Diptera). Zoologica 162: 1-220.

Malloch J.R. 1921 Exotic Muscaridae (Diptera) - I. The Annals and Magazine of natural History, Zoology, Botany and Geology 7 : 161-173.

McAlpine J.F. 1981 Morphology and terminology adults. In: McAlpine J.F., Peterson B.V., Shewell G.E., Teskey H.J., Vockeroth J.R., Wood D.M. (eds). Manual of Nearctic Diptera. Volume 1. Agriculture Canada Monograph 27: 9-63.

Nihei S.S., de Carvalho C.J.B. 2009 The Muscini flies of the world (Diptera, Muscidae): Identification key and generic diagnoses. Zootaxa 1976: 1-24.

Pont A.C. 1969a Afrikanische Musciden (Dipt.). (Ergebnisse der Forschungsreise Lindner 1958/59Nr. 22). Stuttgarter Beiträge zur Naturkunde 201: $1-27$.

Pont A.C. 1969b Studies on Australian Muscidae (Diptera). II A revision of the tribe Dichaetomyiini Emden. Bulletin of the British Museum (Natural History). Entomology 23: 191-286.

Pont A.C. 1978 Diptera Muscidae and Anthomyiidae from the Comoros Archipelago. Faune Entomologique de l'Archipel des Comores. Mémoires du Muséum National D'Histoire Naturelle (N.S.) Série A, Zoologie 109: 333-365.

Pont A.C. 1980 Family Muscidae. In: Crosskey R.W. (ed.) Catalogue of the Diptera of the Afrotropical Region. British Museum (Natural History), London, UK, 721-761.

Séguy E. 1938 Note sur les Anthomyiidae. Encyclopédie entomologique (B) 2 Diptera 9:109-120.

Stuckenberg B.R. 1999 Antennal evolution in the Brachycera (Diptera), with a reassessment of terminology relating to the flagellum. Studia Dipterologica 6: 33-48.
Van Emden F.I. 1942a Keys to the Muscidae of the Ethiopian Region: Dichaetomyia-group [Part]. Annals and Magazine of Natural History, ser. 11, 9: 673-701.

Van Emden F.I. 1942b Keys to the Muscidae of the Ethiopian Region: Dichaetomyia-group [Concl.]. Annals and Magazine of Natural History, ser. 11, 9: 721-736.

Van Emden F.I. 1951 Muscidae C. - Scatophaginae, Anthomyiinae, Lispinae, Fanniinae and Phaoniinae. Ruwenzori Expedition 1934-5 2: 325-710.

Zielke E. 1971 Beitrag zur Kenntnis der Verbreitung afrikanischer Musciden (Muscidae; Diptera). Entomologische Mitteilungen aus dem Zoologischen Museum Hamburg 73: 173-181.

Zielke E. 1972 New Muscidae species from Madagascar (Diptera). Verhandlungen der Naturforschenden Gesellschaft in Basel 82: 145-163.

Zielke E. 1974 Beitrag zur Kenntnis der Verbreitung afrikanischer Musciden (Muscidae: Diptera). Teil III: Sammlung der California Academy of Sciences. Zeitschrift für angewandte Zoologie 61: $1-44$.

Zielke E. 2020 Correction proposals for some Madagascan Dichaetomyia species identified in earlier years, and descriptions of six new species of the genus (Diptera: Muscidae). Entomologist's Monthly Magazine 156: 209-241.

Zielke E. 2021a On the Afrotropical species of Neomyia Walker, 1859 (Diptera: Muscidae). Entomologische Zeitschrift 131: 19-45.

Zielke E. 2021b Descriptions of five new shiny Dichaetomyia species from Madagascar (Diptera: Muscidae). Entomologist's Monthly Magazine 157: 81-103. 